\title{
Assessing Regional Effects Of Income Maintenance Programs: A Guide To Policy Analysis\#
}

\author{
Julie DaVanzo* and David H. GreenberG**
}

\begin{abstract}
The notion that the nation's welfare system has "failed" has become almost universally accepted, but hardly any consensus has developed on what should replace it. From a national perspective, this lack of agreement stems significantly from uncertainty over the ultimate cost of proposed alternatives to the present welfare system and the extent to which these alternatives would alter existing behavioral patterns of those who participate. From a subnational ${ }^{1}$ point of view, the range of uncertainty is even greater. The issues here involve the implications of various proposals for state and local welfare budgets and the geographic allocation of federal transfer payments to the poor, and the proposals' differential regional effects on various dimensions of human behavior. In fact, some of these behavioral effects, such as changes in the migration flows of people or physical capital, are subnational by nature. Others, such as changes in labor supply, may differ substantially from one area to another.
\end{abstract}

This paper is concerned with research issues that must be faced in assessing the potential subnational effects of proposed income maintenance programs, a job that has barely just begun. The paper is divided into discussions of four major tasks that must be performed by policy analysts if they are to help policymakers evaluate these effects. The first of these tasks is simply to list program provisions that may have important subnational effects, either directly or by changing the behavioral patterns of participating families. Examples of spheres of behavior that income maintenance legislation may affect include labor supply, the propensity to migrate, investments in human capital (such as in schooling and on-the-job training), consumption patterns, the propensity to marry and to stay married, and fertility. The second task is to construct a set of socioeconomic indicators whereby these effects can be gauged in a manner readily comprehensible to policymakers. The third task is to develop an appropriate theoretical framework for analyzing behavioral changes systematically. The fourth task involves obtaining the information necessary to estimate the magnitude of program effects, that is, to predict the changes in the socioeconomic indicators that would result

\#This paper is based on a larger study (Julie DaVanzo and David H. Greenberg, Suggestions for Assessing Economic and Demographic Effects of Income Maintenance Programs, R-1211-EDA, The Rand Corporation, June of 1973) that was supported by the Office of Economic Research of the Economic Development Administration, Department of Commerce. The authors are grateful to Rand colleagues William P. Butz, Dennis N. DeTray, Peter A. Morrison, Gary Nelson, and Anthony H. Pascal, and to T. Paul Schultz of the University of Minnesota for commenting on earlier drafts of this paper.

*The Rand Corporation, Santa Monica.

**Office of Income Security Policy/Research, Department of Health, Education, and Welfare, Washington, D.C. 
from adoption of the proposed income maintenance alternatives under consideration.

Successful completion of these tasks depends on resolving a set of fundamental research issues that do not change as the geographic dimension of primary interest varies. Thus, although all the topics discussed in this paper are relevant to assessing the potential subnational implications of alternative income maintenance programs, many are equally pertinent to examining potential national effects.

\section{PROVISIONS OF INCOME MAINTENANCE PROGRAMS}

Income maintenance systems encompass one or more of the following program components: negative income tax plans, wage subsidies, government-created jobs, and income-in-kind programs such as food stamps and subsidized housing and medical care. The income maintenance programs most intensively investigated by social scientists and most seriously considered by Congress over the last few years, such as the Family Assistance Plan (FAP), are those incorporating negative income tax features; for purposes of illustration, we shall also generally refer to this type of program. However, most of the points we make are also relevant to other types of income maintenance programs.

In discussing negative income tax programs (or other income maintenance programs), researchers have tended to emphasize the two most prominent program parameters: the base level of support and the tax rate. The base level of support defines the income guarantee-that is, a floor under household income. Viewed somewhat differently, the base level of support is the maximum income transfer a household can receive under the program. In general, the transfer amount is reduced as more income is received from nonprogram sources. In effect this means that nonprogram income is taxed. The proportion of nonprogram income that is subtracted from the base level of support is commonly referred to as the program tax rate.

The values of the guarantee level and tax rate for any negative income tax plan actually implemented will probably vary among classes of households, depending on provisions for coverage, work regulations, the accounting period, the treatment of different sources of income, and how the program is linked to other income maintenance programs, such as social security and unemployment compensation. Through these provisions, households are, in effect, assigned to various administrative categories, each of which is associated with a unique set of tax rates and guarantees. For example, under the existing welfare system or under various proposed forms of FAP, the base level of support increases with the size of the household. Many negative income tax proposals would also provide higher guarantee levels (and higher tax rates) for households headed by persons of retirement age. On the other hand, childless persons who have not yet reached retirement age are entirely excluded from program benefits under many proposals. Guarantee levels and tax rates for households are also likely to vary by geographic location, the precise extent of the variation being contingent upon program provisions for cost-of-living adjustments and for state supplementation of federal in- 
come transfers. Proposed legislation to replace the present welfare system by a program such as FAP would tend to dampen, but not eliminate, existing regional variation in program parameters.

\section{SOCIOECONOMIC INDICATORS}

An important requirement for analysis of income maintenance programs is the formulation of socioeconomic measures that clearly show program effects to policymakers. The goal of income maintenance research should be to predict accurately the values of such indicators under alternative programs. Comparisons with pre-program values for these indicators would then allow potential programinduced changes to be estimated. The indicators should be sufficiently flexible to satisfy the particular needs of different sets of policymakers-for example, those at the regional as well as the national level-but there must not be so many of them as to overwhelm their users in a sea of numbers.

Projected changes in the indicators should be calculated for various geographical regions, as well as for the nation as a whole. Some of the potential effects of income maintenance programs, such as changes in the migration patterns of people or physical capital, are essentially subnational by nature and will cancel out if examined only at the national level. In addition, for several reasons, even effects that can be measured at a national level, such as changes in labor supply, may differ substantially among areas. First, as mentioned above, the provisions of an income maintenance program may vary geographically. Second, the proportion of persons eligible for income maintenance payments will not be the same in each location since some areas contain more poor families than others. Third, the demographic composition of various subnational populations differs, and different demographic groups-for example, various age groups-may respond differently to an income maintenance program. Fourth, behavioral response parameters, even for a given demographic group, may vary geographically. Computing changes in the indices for separate geographic areas permits examination of the regional allocation of program transfer payments. It also allows assessment of the effects of alternative income maintenance programs on each region's economy.

The indicators must convey several different types of information. These are discussed below.

\section{Effects on Poverty}

Presumably, the raison d'être for income maintenance programs aimed at the poor is the mitigation, if not the eradication, of poverty. The effectiveness of a program as an anti-poverty device is perhaps most naturally measured by comparing the number of persons or households who would be poor if the program were implemented with the number who would be poor were it not. One difficulty with this measure is in finding an operational definition of "poverty". A poverty line - a money income level sufficiently high to bring a family out of povertymust be determined. The most commonly used poverty lines are federal standards, which were initially developed in 1964 by the Social Security Administration 
and are adjusted annually for changes in price levels. Although most users of these standards acknowledge that they are arbitrary, and considerable controversy rages over whether they are set too high or too low, they are probably adequate for comparing alternative income maintenance programs at a national level. However, for regional analysis, there is the additional problem of defining regional cost of living indices appropriate for deflating these poverty threshholds so that they typify equivalent levels of poverty for families in different geographic areas. $^{2}$

It may not be sufficient to compare these programs by simply counting the number of persons or families who cross a poverty line. A program that concentrated only on those whose incomes are slightly below the poverty line might then be judged superior to another program that actually did more to alleviate poverty but concentrated on those whose incomes are far below the poverty line. For this reason, it may be better to assess the effects of the program on the basis of the total amount by which incomes that fall below the poverty line are in fact raised (that is, by how much the aggregate "poverty gap" is reduced).

\section{Budgetary Costs}

Public discussions of the "costs" of proposed income maintenance programs are usually concerned with the amount of income transfers that will actually be paid, the administrative costs, and changes in expenditures in existing programs that are associated with the introduction of the new programs. It is particularly important that such budgetary costs be projected separately for different units of government, since a budgetary increase at one level of government, say the federal, may in part be offset by a budgetary decrease at another level, say the state. Had FAP been implemented such a transfer from state to federal responsibility might have been one of its more important effects.

\section{Market Output}

Changes in transfer payment expenditures do not necessarily reflect program effects on the real resources that are used by an economy. These effects will be partly reflected by program-induced changes in the earnings of participants-a measure of the market output these persons produce-and, at a more aggregate level, by changes in the Gross National Product or in measures of regional output.

\section{Demand for Government-Provided Goods and Services}

Program-induced changes in behavior may result in increased or decreased use by the poor of such publicly provided goods and services as education, medical care, and the State Employment Service. Such changes will be reflected by the budgetary expenditures for these services and by changes in the educational attainment and the wage rates of the poor.

\section{Distribution of Income}

Almost by definition, the income transfers provided by a new income maintenance program will change the distribution of income among income classes, 
demographic groups, and geographic regions. Projection of these changes will indicate which groups will be relatively better off and which will be relatively worse off. Potential program distributional effects may be estimated by projecting the total post-program disposable personal income of each income group.

\section{Population Distribution}

Later, we suggest a number of reasons why income maintenance programs may influence family migration decisions. Program effects on migration should, of course, be indirectly reflected by the socio-economic indicators that are used to measure many of the program effects discussed above, such as those on market output within a geographic area, on interregional income distribution, and on state and local welfare budgets. Nevertheless, migration is a sufficiently important policy area that policymakers should also be provided direct measures of program-induced changes in the number and demographic composition of migrants to and from various regions.

\section{Nonmarket Activities}

Although the indicators listed above are rather conventionally used, they tend to provide only limited perspective on program effects on the social welfare. For example, changes in the aggregate poverty gap or in family income are usually measured in dollar terms. However, if a family withdraws so many hours from the labor market after a program is implemented that its money income actually decreases, this does not mean that the family is worse off, at least from its own perspective. Reduction of its time in the labor market implies that it feels this time is now more valuably spent engaging in nonmarket activities. A family's well-being includes returns from time spent outside the labor market as well as from time spent in the market.

\section{Political Acceptability}

Income maintenance programs that cause uneasiness among nonparticipants, many of whom pay for the program, are likely either not to last very long orlike the current welfare system - to engender attempts to tighten eligibility requirements and to punish welfare "cheaters". Thus, it is useful to anticipate potential sources of such dissatisfaction on the part of non-participants as early as possible. Several of these, such as budgetary costs and income distributional effects, are captured by some of the indicators already mentioned. Two other potential sources of dissatisfaction on the part of taxpayers may be (1) reductions in work effort by transfer payment recipients, as measured by changes in the number of such persons who participate in the labor force and in the number of hours they work, and (2) increases in the number of persons receiving transfer payments-that is, increases in the welfare case load.

\section{PROGRAM-INDUCED CHANGES IN BEHAVIOR}

Predictions of program-induced changes in the socioeconomic indicators discussed above require knowledge of how individual behavior adjusts in response 
to various program provisions. Obtaining this knowledge depends, in turn, on guidance from economic theory. ${ }^{3}$ Economic theory indicates that behavioral changes following the introduction of an income maintenance program can be traced to three major sources:

1. A new program will change the income and wealth positions of some households, consequently changing the amount and possibly the mix of commodities these households consume. Since these commodities are produced at home by combining market goods and the time of family members, a change in the demand for commodities will affect the derived demands for time and goods, and hence the household's allocation of time among home and labor market activities and its purchases of market inputs may change.

2. Some types of income, such as interest, rents, and transfer payments from other programs, may be taxed more heavily than others under the new program. One would expect households to tend to shift their efforts toward obtaining those types of income that are subject to relatively low tax rates. Moreover, there is one particular type of "income" that will not be taxed at all: the value a household places on goods and services that it does not purchase in the market place but produces itself (home repairs, for example). In other words, the time exchanged for market goods and services-time in the labor market-is taxed under income maintenance programs, but time spent producing nonmarket goods and services or used directly in consumption activity is not. As a consequence, commodities that require large inputs of goods and services purchased in the market become more expensive to households relative to those that require large amounts of nonmarket time. The relative consumption of the first type of commodity should, therefore, decline.

3. It was noted earlier that income maintenance programs usually establish various categories, each associated with a different set of tax rates and income guarantee levels. Other things equal, households will tend to tailor their behavior (by getting married or having a child, for example) so that they will be placed in the category that offers them the most advantageous terms.

In the following subsections, we provide several more specific illustrations of how types of behavior might be affected by introduction of a new income maintenance program and how behavioral adjustments to income maintenance programs will, in turn, be reflected by changes in the socioeconomic indicators discussed earlier.

\section{Changes in Labor Supply}

Several different provisions of negative income tax programs may affect the labor supply of participating households. First is the income subsidy paid under such programs. Workers can use at least part of this subsidy to replace earnings given up by choosing to work fewer hours. In other words, the subsidy can be used to "purchase" time to engage in nonmarket activity. Second, such programs impose a tax rate on earnings, thereby changing the amount of market goods and services that can be obtained in return for an hour's work, but not the value of productive time spent outside the labor market. Third, program provisions may 
stipulate that under certain conditions failure to accept a job offer will cause the amount of the subsidy to be reduced.

The range of empirical estimates of the labor supply response to the introduction of an income maintenance program is currently unacceptably large. ${ }^{4}$ For programs similar to the Family Assistance Plan, estimates of the national labor supply reduction for prime-age males based on non-experimental data have ranged from 0 to over 30 percent; ${ }^{5}$ the information so far available from income maintenance experiments implies that only a small reduction in the hours of prime-age males will take place. ${ }^{6}$

Especially little is as yet known about whether labor supply parameters vary geographically, although preliminary evidence from at least one study suggests that regional variation may be rather substantial. ${ }^{7}$ There are a number of reasons to anticipate such variation. For example, "tastes" for work will vary with the in-" fluence of the work ethic or the precept that "a woman's place is in the home." Differential availability of public transportation may affect the fixed costs of working. Factors such as the weather and nearby recreational opportunities will influence the opportunity costs of time in the market. Similarly, houses may require more time for upkeep in some areas than in other areas, or some regions may offer greater opportunity for nonmarket production, such as growing one's own food. On the other hand, it may be relatively less expensive in some regions to substitute market goods or services for one's own time in household production. The relatively low price of servants in some parts of the South is an obvious example.

Policymakers have at least five reasons to be concerned about the magnitude of the labor supply response to the introduction of an income maintenance program:

1. The number of hours worked is a major determinant of the amount of goods and services produced by the economy.

2. The transfer costs of the program depend on the work effort of participants. For example, if participants reduce their hours of market work, thereby causing their earnings to fall, part of this loss of earnings will be replaced by program-sponsored income transfers.

3. Presumably one goal of policymakers in designing income maintenance programs for the poor is to improve participants' money incomes. Since most negative income tax progiams would replace only part of any earnings loss resulting from an hours reduction, such a reduction would lessen program effectiveness in increasing the money incomes of the target population.

4. The political acceptability of the program also hinges on its effect on labor supply. The Protestant ethic implies that work is good per se and especially good for the poor. Thus, policymakers and taxpayers seem much less resistant to subsidy payments that are used by poor households to purchase goods and services than they are to payments used to replace earnings losses caused by a reduction in market work. 
5. Changes in hours worked may alter the geographic allocation of the supply of low-wage labor, especially if wage and income response parameters vary geographically. Thus, firms may relocate.

These areas of concern are to some extent accounted for by the socioeconomic indicators discussed earlier. For example, attitudes of taxpayers toward the program and its participants are likely to be most affected by the magnitude of the changes in total hours worked and by changes in the number of welfare recipients who participate in the labor force. However, changes in the output of market goods and services that these hours adjustments entail are best measured by aggregate changes in earnings. Program budgetary costs are directly measured by the change in total welfare transfer payments resulting from implementation of the program, and program effectiveness in improving the money incomes of the poor is reflected by changes in the total disposable personal income of participants and by changes in the aggregate poverty gap.

\section{Changes in Human Migration Flows}

Among other reasons, people may migrate because a new area offers better employment opportunities, greater consumption returns (for example, a superior climate or the opportunity to live closer to relatives), lower living costs, and, perhaps, in the case of some poor families, superior income maintenance programs. By changing the level of income supplements available to certain households and the set of tax rates that these households face, any new income maintenance program will affect the likelihood of moving for one or more of these reasons. The mechanisms through which these factors operate are briefly summarized here. ${ }^{8}$

The income supplement associated with a negative income tax program will increase the gross flow of migrants by facilitating the financing of migration, subsidizing job search, and providing income insurance in a new area. On the other hand, the tax rate on earnings, if higher than what the family is currently facing, will reduce a recipient family's potential earnings in all locations and thus decrease the absolute earnings differential available by moving to a new location; this should weaken the incentive to search for and migrate for better job opportunities. However, a higher tax rate will also reduce any earnings foregone during the time the migrant is between jobs. This will tend to mitigate the negative effect on migration of a smaller labor market return.

At present the average monthly welfare payment per recipient varies considerably among states. ${ }^{9}$ It has been alleged that these interstate discrepancies encourage "nonproductive" migration from low-benefit states to those with more attractive programs. ${ }^{10}$ Congressionally enacted welfare reform measures are likely to establish national standards that reduce the discrepancies in interstate welfare payments, although the extent to which this happens will depend on provisions for state supplements and cost-of-living adjustments. This should reduce any existing welfare-motivated migration, although return migration from states that presently offer high welfare benefits to those that pay low benefits may increase. In addition to the effects of income supplements and tax rates, income 
maintenance programs may also facilitate migration through provisions for moving allowances, job locations, and information services.

Partly because of the multiplicity of possible effects proposed income maintenance programs may have on migration behavior, existing empirical studies of migration are inadequate for predicting how net migration between given pairs of regions would be affected. In fact, it is not even clear at the present time whether the implementation of an income maintenance program would increase or decrease the proportion of the population that changes residence during a given time period. It is important, however, that policymakers be provided with this information. Along with the other program behavioral effects, the changes in the sizes and compositions of regional populations that result from the effects of income maintenance programs on the volume, direction, and demographic composition of migration flows will determine the regional distribution of program transfer payments. Program-induced population redistribution also can be expected to have important consequences for regional economic growth and development.

\section{Changes in Consumption Patterns}

Changes in income levels and tax rates that result from the introduction of a new income maintenance program have obvious implications for consumption patterns. For example, if income increases, other things equal, a family will buy larger quantities of all goods whose income elasticities exceed zero, and will especially increase its consumption of commodities with very high income elasticities. ${ }^{11}$ Some of these increases in expenditures will be recirculated through the economy and, through "multiplier effects," should generate additional increases in expenditures, outputs, and incomes. ${ }^{12}$ These will be reflected by changes in disposable personal income and in other socioeconomic indictors for the nation as a whole and for subregions.

However, the extent and direction of multiplier effects are unclear, a priori. First, any change in transfer income receipts that follows the adoption of an income maintenance program may be at least partly offset by an opposite change in earnings. This would occur, for example, if a program that increases transfer receipts also induces a reduction in hours of work and, hence, in earnings. Second, if a new program is funded through a tax increase, any increase in transfer income received by participating families may be offset by a corresponding reduction in the disposable personal income available to nonparticipating families. Of course, if the marginal propensity to consume of the low-income recipient population exceeds that of the nonrecipient population, positive multiplier effects may still be produced. Moreover, the geographic distribution of income is almost certain to change. Thus, positive multiplier effects may be produced in regions with a disproportionate number of poor persons and negative multiplier effects occur in wealthier areas.

In addition to changing the magnitude and composition of recipients' income, an income maintenance program that taxes wages will change an important component of the cost of consumption: the price of time. As mentioned previously, such a program would tax time spent working (market time), but would not 
tax productive nonmarket time. One possible consequence of this is that children -which can at least partially be viewed as a consumption good-may become more attractive to households because the earnings that are forgone by staying home and caring for them have, in effect, been reduced.

Another feature of specific forms of income maintenance legislation that may also increase the demand for children is the provision in many proposed programs that no family can receive benefits unless it has at least one child. In addition, even after a family qualifies for benefits, the guarantee level under many proposed income maintenance programs is positively related to family size. For example, under H. R. 1 the marginal value of the first child to a couple with no non-program income would have been the base level of support, $\$ 2000$ a year; the marginal values of a second and third child, $\$ 400$ each. Thus, if a child adds less to household costs (both psychic and monetary) than the value of welfare benefits, the family might restyle their lives-that is, have a child they might not otherwise have had-in order to move into the recipient class or receive additional benefits. Furthermore, some programs include provisions for subsidized day care. This may have a positive effect on desired family size by reducing the time cost of children.

Through its income and price effects, the imposition of an income maintenance program will affect a family's demand for publicly provided services as well as its demand for private goods. Important examples of such services are publicly funded schools and subsidized medical care. The money price of these services to recipients is either zero or very low. A major (if not the only) cost of such services to the recipient is the time that must be used in their consumption. ${ }^{13}$ In other words, the consumption of public goods tends to be very time intensive. Thus, any increase in tax rates that results from imposition of a negative income tax program should produce an increase in the demand for public goods. ${ }^{14}$

\section{Changes in Human Capital Investments}

The primary types of investments made by likely participants in income maintenance programs are those in their own human capital-schooling, on-the-job training, and so forth. Since investments in human capital typically require sizable inputs of time, the effects of changes in income levels and tax rates on such investments should be similar to the effects of such changes on time-intensive commodities. For example, an increase in tax rates on earnings would be expected to increase the demand for job training and other forms of human capital by reducing the opportunity costs of such investments. ${ }^{15}$ Program-associated increases in income levels should increase the demand for investments in human capital by facilitating their internal financing. ${ }^{16}$ The fact that income maintenance programs place a floor under income may also encourage investments in human capital because many forms of investments in human capital, such as migration, job search, and specialized training, tend to be relatively risky ventures; by reducing future variance of income, the income floor reduces the risk associated with the investment.

Therefore, any new income maintenance program that raises the income levels and tax rates of its participants is also likely to increase the number of 
households willing to invest in human capital. Assuming a corresponding increase in the supply of sources of those investments, such as training facilities, the long-run result could be an increase in the market earnings of such families and, hence, a decrease in their participation in the programs.

\section{OBTAINING INFORMATION ON THE EFFECTS OF INCOME MAINTENANCE PROGRAMS}

Our previous discussion indicates that to measure the effects of income maintenance programs, one must first estimate the direction and magnitude of behavioral responses to program-related changes in wage rates and family income. The two principal alternative approaches to obtaining information on how wage and income changes affect behavior are through data generated by controlled social experiments and through inferences from non-experimental data collected by household surveys.

Under either approach, a critical issue for determining the regional implications of income maintenance programs is the extent to which behavioral responses to wage and income changes vary geographically. To minimize administration costs, social experiments are almost always confined to relatively small geographic areas; thus, the question of their applicability to regions not covered by the experiment is of obvious importance. As opposed to experimental data, most of the better non-experimental data are based on national samples of households. However, it is frequently impossible to divide such national samples into subsamples that closely correspond to the regions of interest. ${ }^{17}$ In addition, as a sample is subdivided, subsamples can become quite small. This problem is compounded because, in addition to regional variation in behavioral parameters, it is also important to know whether the parameters vary by size of place, age, race, sex, and so forth. As the number of observations in a subsample shrinks, the reliability of inferences based on that subsample is weakened.

\section{The Experimental Approach}

Under the social experiment approach, a sample of selected households is randomly divided into subgroups. Wage and income conditions are then made to vary among the groups and the behavior of the groups compared. For example, households that participate in a pilot program can be compared with a control group of similar households that do not participate.

The obvious advantage of this approach is that it allows behavioral response conditions to be estimated under circumstances that are as close as possible to those that would exist under an actual program. Nevertheless, it is not really possible to duplicate program conditions accurately in all respects. Results from an experiment may be distorted by the intrusion of unforseen changes in environmental conditions that are not subject to experimental control ${ }^{18}$ or by households that do not adjust their behavior during a temporary experiment in the same way they would if the change were permanent. ${ }^{19}$ An additional problem is the so-called Hawthorne Effect: Families who are being observed continously may behave differently from other families with similar characteristics simply because they are being studied. 
Possibly the most serious drawbacks of social experimentation have to do with cost and time constraints. Such experiments are relatively costly, although it is important to recognize that much of the "cost" in an income maintenance experiment may be payments made to the low-income persons participating in the experiment. Nevertheless, administrative costs are sufficiently large that experiments tend to be carried out in fairly narrow geographic areas, bringing into question the applicability of their results to all regions of interest. In addition, experiments do not generate results until considerable time has elapsed; policymakers may not be able to wait until relevant experimental results are available.

\section{The Nonexperimental Approach}

Because experimental data are expensive and time-consuming to generate and are subject to biases of unknown magnitude, it is important to consider estimating behavioral parameters from nonexperimental data, especially data that are already available. Particularly important is the use of such data to test whether behavioral response parameters vary across regions, thereby helping to determine whether the results of a social experiment carried out in one geographic area are applicable to other areas.

As in the case of social experiments, making inferences from non-experimental data involves comparing the behavior of households for whom wage or income conditions differ. With nonexperimental data, differences among households are not artificially induced but are observed under existing conditions; this approach is sometimes referred to as a "natural experiment." Unlike controlled experiments, differences among households in variables other than those of policy interest cannot be "held constant" by dividing a sample into randomly selected experimental and control groups but must be controlled through various statistical techniques.

Although progress has been made in learning how to use nonexperimental data to estimate behavioral parameters, substantial gaps remain and empirical results have so far been of limited usefulness to policymakers. There are several reasons for this. Even though the conceptionally correct definitions of the variables whose relationships are to be estimated are usually clear, the transition from theoretically correct variables to measurable variables is extremely difficult. The statistical technique used for estimating the relationships among the variables, once measured, must deal correctly with the simultaneity in household decisionmaking; that is, it must take account of the fact that one type of behavioral response by an individual-say, a labor supply adjustment-is interdependent with other areas of behavior and with the characteristics of other members of the household. Finally, the relations estimated between the variables may be very sensitive to the sample of households or individuals that is drawn from the nonexperimental data.

The least tractable of the problems involved in estimating the behavioral parameters tend to derive from the same source: In a "natural experiment" there may simply be too few occasions when circumstances sufficiently approximate those that would occur upon introduction of an income maintenance pro- 
gam; that is, we may seldom, if ever, observe in nonexperimental data families' reactions to truly exogenous changes in wage rates and income. Changes in these variables that would result from introduction of an income maintenance program are outside the affected households' control. Wage and income differences that are observed nonexperimental data, however, may have been strongly influenced by decisions made by the sampled households.

\section{CONCLUDING SUMMARY}

Table 1 summarizes many of the topics discussed in this paper. The first four columns of the table indicate how various behavioral areas may be affected by the different provisions of income maintenance programs. The directions of the effects are indicated whenever possible. For example, the income guarantee associated with most income maintenance programs is expected to reduce hours of work by serving as a substitute for earnings; but to increase migration by helping to cover the cost of moving to a new area and of searching for a new job, and by providing some income "insurance" if a new job cannot be immediately found. Various behavioral effects of program tax rates and other program provisions are also listed in the table.

Table 1 also implies that behavioral responses to program provisions are, in turn, reflected by changes in different types of socioeconomic indicators. Since most of the behavioral effects will, in one way or another, affect most socio-economic indicators, only a single arrow is used to suggest the relation. For example, among other things, labor supply effects determine the distribution of transfer payments under a program, the market output produced by program participants, and the ultimate cost of the program. Program effects on migration would change the interregional income distribution, market output within an area, state and local welfare budgets, and, of course, the population distribution.

In addition to affecting the indicators indirectly through behavioral adjustments, a new income maintenance program will change several types of socioeconomic indicators directly via its transfer payments. That is, certain indices, such as those indicating the extent of poverty or how income is distributed, would be affected by transfer payments even if no behavioral adjustments were made to adoption of an income maintenance program. As the right-hand side of Table 1 indicates, the size of these transfer payments is determined, of course, by program tax rates, guarantee levels, and other program provisions.

Table 1 suggests that for some behavioral areas, such as labor supply, we can be fairly certain a priori about the direction of the effects of income maintenance programs. However, for other areas, such as migration, there are several counter-balancing effects and the net result is uncertain. What are presently not available for any of the behavioral areas are very precise predictions of the magnitudes of the behavioral effects, particularly at the sub-national level. Empirical attempts to estimate the size of income maintenance program effects are still at a fairly preliminary stage in terms of yielding reliable information to policymakers, and those research efforts that have been made have concentrated mostly on national effects. We recommend that greater future emphasis be placed on the regional implications of proposed income maintenance programs. 
TABLE 1

EFFECTS OF PROGRAM PROVISIONS ON SELECTED

BEHAVIORAL AREAS AND SOCIO-ECONOMIC INDICATORS

Program-Induced Changes in Behavior

Behavioral Areas

Socio-economic Indicators

Program Effects on

Program Provisions

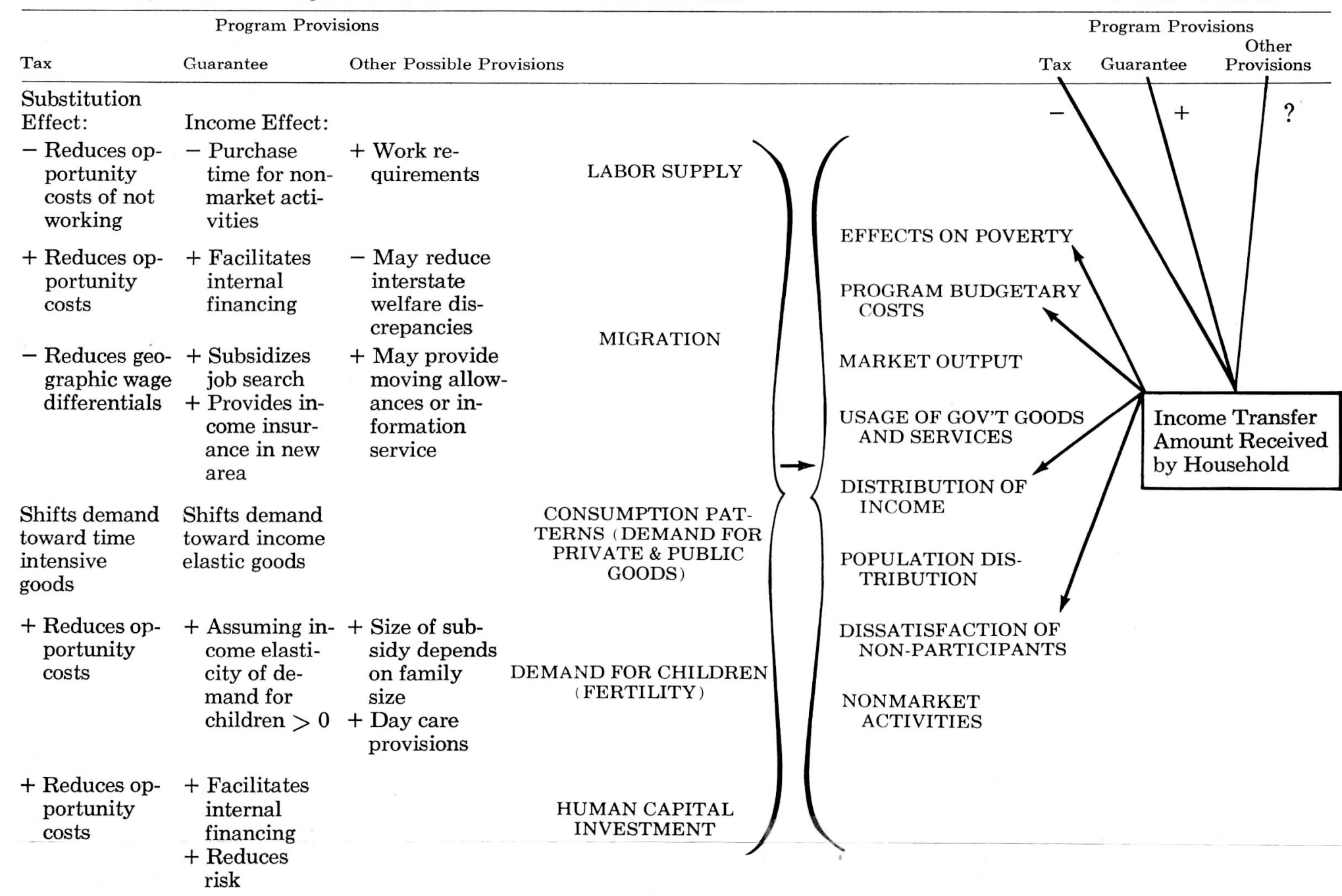




\section{FOOTNOTES}

IIn the term "subnational" we include any geographic entities-regions, states, cities, rural areas, urban areas, etc.- that are of policy interest. Except when otherwise indicated, our comments apply equally to all geographic units of interest.

2For one such attempt see Harold W. Watts, "The Iso-Prop Index: An Approach to the Determination of Differential Poverty Income Threshholds", Journal of Human Resources, Vol. II, No. 1, Winter 1967, p. 3-18.

3The particular theoretic framework that we feel is most appropriate for examining the behavioral implications of income maintenance programs is the "household production model." (See Gary Becker, "A Theory of the Allocation of Time," Economic Journal, Vol. 75, September 1965, pp. 493-517, and Kelvin J. Lancaster, “A New Approach to Consumer Theory,” Journal of Political Economy, Vol. 75, April 1966, pp. 132-157, for the seminal articles on this model. For expositions of this model in the context of welfare reform analysis, see Dennis N. De Tray, A Conceptual Basis for the Study of Welfare Reform Effects, R-1066-DOC, The Rand Corporation, Santa Monica, September 1972; Dennis N. De Tray, A General Economic Framework for Welfare Reform Analysis, R-1346-OEO, The Rand Corporation, July 1973; and James P. Smith, Family Decisionmaking Over the Life Cycle: Some Implications for Estimating the Effects of Income Maintenance Programs, R-1121-EDA/OEO, The Rand Corporation, November 1973.) This model has several important advantages for such studies: (1) The family is the decisionmaking unit in this model; decisions about the types of behavior likely to be affected by welfare reform are made in a family context; (2) the model has been extended to study changes in family behavior over time; (3) the model measures individual and family well being by their "full income"-the value of all their time, including time spent in productive nonmarket activities such as rearing children-and not merely by their money income and thereby allows many different dimensions of behavior to be analyzed.

4See G. C. Cain and H. Watts (eds.), Income Maintenance and Labor Supply: Econometric Studies, Markham Press, Chicago, 1973; and Julie DaVanzo, Dennis N. De Tray, and David H. Greenberg, Estimating Labor Supply Responses: A Sensitivity Analysis, R-1372-OEO, The Rand Corporation, Santa Monica, December 1973.

5Cain and Watts, op. cit.

6See the papers on the New Jersey Income Maintenance Experiment in Spring 1974 issue of the Journal of Human Resources.

7David Greenberg (Income Guarantees and the Working Poor in New York City: The Effect of Income Maintenance Programs on the Hours of Work of Male Family Heads, R-658-NYC, March 1971) has estimated labor supply functions for (1) a national sample, (2) central cities, (3) large central cities, and (4) New York City. He has found the parameters to differ considerably among the four samples.

8These are discussed in greater detail in Julie DaVanzo, An Analytical Framework for Studying the Potential Effects of an Income Maintenance Program on U.S. Interregional Migration, R-1081-EDA, The Rand Corporation, Santa Monica, December 1972; and Julie DaVanzo "Assessing the Potential Impact of an Income Maintenance Program on Migration: Hypotheses and Suggestions for Research," P-5006, The Rand Corporation, Santa Monica, May 1973.

9For example, in 1972 the maximum monthly payment to a family of four (mother and three children) with no other income was $\$ 60$ in Mississippi, but exceeded $\$ 380$ in several counties in New York. ("Welfare in the '70's: A National Study of Benefits Available in 100 Local Areas", Studies in Public Welfare, Paper \#15, prepared for the Subcommittee on Fiscal Policy of the Joint Economic Committee, Congress of the United States, Government Printing Office, Washington, 1974.) R. A. Cloward and F. F. Piven, "Migration, Politics, and Welfare," Saturday Review, November 16, 1968, point out that eligibility requirements and administrative procedures also exhibit considerable interstate variation.

${ }_{10}$ For examples of such allegations see the list of quotes in Robert D. Reishauer, "The Impact of the Welfare System on Black Migration and Marital Stability," Columbia University, Ph.D. dissertation, 1971, p. 68, footnote 74. Available evidence does not lend very strong support to the hypothesis that (potential) welfare recipients tend to move to areas with attractive welfare programs. However, most studies have considered only interregional discrepancies in benefits, neglecting differences in eligibility requirements and administrative procedures.

11A staff study sponsored by the President's Commission on Income Maintenance Programs tentatively concluded that "for most [poor] persons 50 to 70 percent of any increment in income will be spent on the three basics, food, clothing, and shelter" and that "substantial portions of additional expenditures would be devoted to transportation, tobacco and alcoholic beverages, and reading, recreation and education." See Chapter 4.1 on "Household Consumption," in Background Papers, President's Commission on Income Maintenance Programs, 1970, pp. 79-84.

12For a more detailed discussion of the macroeconomic implications of a negative income tax program, see Christopher Green, "A Macroecoonmic Analysis of the Ecoonmic Impact of Negative Income Taxes," in Technical Studies, President's Commission on Income Maintenance Programs, 1970, pp. 101-119.

13Recent empirical studies of the demand for medical services have indicated that time-price elasticities tend to rise as money prices fall. See Jan Acton, Demand for Health Care Among the Urban Poor, with Special Emphasis on the Role of Time, R-1151-OEO/NYC, The Rand Corporation, Santa Monica, 
April 1973; and Charles Phelps and Joseph Newhouse, Coinsurance and the Demand for Medical Services, R-964-OEO, The Rand Corporation, Santa Monica, April 1973.

${ }_{14} \mathrm{~A}$ tax on earnings will reduce the time price of consuming public goods for individuals with market options for their time; it will not necessarily increase the demand for such goods for persons who do not customarily participate in the labor force, for example, young children. An increase in tax rates on wages may encourage older children to stay in school longer, but have little effect on school attendance by younger children.

${ }_{15}$ However, this incentive may be offset if post-investment earnings remain sufficiently low that the investor is still eligible to participate in the program. In this case, the tax rate will lower the eventual return expected as a result of investments in human capital.

16The receipt of program funds may also increase a person's ability to borrow from external sources because the income floor decreases the risk of default.

17Ideally, one would like to have data that give the household's area of residence by a relatively small geographic unit, such as state, SMSA, or county. Unfortunately, many household-level data sets suppress detailed information on residence to maintain confidentiality and provide information only on larger geographic units such as the nine Census divisions or four Census regions. The level of geographic detail available in five individual-level data sets is noted in DaVanzo and Greenberg, Op. Cit., pp. 67-71.

18 For example, interpretation of the results of the income maintenance experiment in Seattle was severely complicated by a drastic increase in the city's unemployment rate during the experimental period. See Mordecai Kurz and Robert G. Spregelman, "The Seattle Experiment: The Combined Effect of Income Maintenance and Manpower Investments," The American Economic Review, 61, No. 2, May 1971, $22-29$.

19See Charles Metcalf, "Making Inferences from Controlled Income Maintenance Experiments," American Economic Review, June 1973, and James P. Smith, op. cit. 